ISSN 1981-416X

\title{
Estratégias para o trabalho colaborativo: revisitando o uso de fóruns on-line na educação a distância
}

\author{
Strategies to collaborative work: \\ revisiting the use of online forums in distance education
}

Estrategias para el trabajo colaborativo:

revisitando el uso de los foros online en educación

a distancia

\section{Daniela Melaré Vieira Barros ${ }^{[a]}$, Vanessa Matos dos Santos ${ }^{[\mathrm{b}]}$, Cristina Sánchez Romero[c]*}

\author{
[a] Universidade Aberta de Lisboa (UAb), Lisboa, Portugal \\ [b] Universidade Federal de Uberlândia (UFU), Uberlândia, MG, Brasil \\ [c] Universidad Nacional de Educación a Distancia (UNED), Madrid, Espanha
}

\section{Resumo}

Como os fóruns on-line podem ser espaços estratégicos para o desenvolvimento de habilidades colaborativas para aprendizagem? O presente estudo partiu deste questionamento e focalizou a interação de estudantes portugueses e espanhóis em fóruns on-line de discussão em duas disciplinas da área da Educação ofertadas pela Universidade Aberta (UAb)

\footnotetext{
*DMVB: Doutora em Educação, e-mail: daniela.barros@uab.pt VMS: Doutora em Educação, e-mail: vanessamatos@ufu.br CSR: Doutora em Educação, e-mail: csanchez@edu.uned.es
} 
de Portugal e pela Universidade Nacional de Educação a Distância (UNED) da Espanha. Os dados interacionais foram coletados e analisados qualitativamente em função de diferentes estratégias didáticas desenvolvidas pelos docentes. Os resultados revelaram distintas abordagens estratégicas que podem ser utilizadas em fóruns on-line como, por exemplo, a diversificação dos tipos de questões propostas e as atividades solicitadas, envolvendo diversos formatos de interação e participação nesses espaços de aprendizagem.

Palavras-chave: Fórum on-line. Educação a distância. Colaboração. Aprendizagem colaborativa.

\begin{abstract}
How can online forums be strategic spaces for the development of collaborative learning skills? The present study started from this questioning and focused on the interaction of Portuguese and Spanish students in online discussion forums in subjects related to Education and offered by the Open University (UAb) of Portugal and the National University of Distance Education (UNED) of Spain. Interaction data were collected and analyzed qualitatively in function of different didactic strategies developed by the teachers. The results revealed different strategic approaches that can be used in online forums such as the diversification of the types of questions proposed and the activities requested, involving several formats of interaction and participation in these learning spaces.
\end{abstract}

Keywords: Online forum. Distance education. Collaboration. Collaborative learning.

\title{
Resumen
}

¿Cómo los foros en línea pueden ser espacios estratégicos para el desarrollo de habilidades colaborativas para el aprendizaje? Este estudio partió de esta investigación y se centró en la interacción de los estudiantes de Portugal y España en los foros de discusión en línea sobre temas relacionados con la educación y que ofrece la Open University (UAB) de Portugal y la Universidad Nacional de Educación a Distancia (UNED) de España. Los datos 
interactivos fueron recolectados y analizados cualitativamente en función de diferentes estrategias didácticas desarrolladas por los docentes. Los resultados revelaron distintos enfoques estratégicos que pueden ser utilizados en foros en línea, como por ejemplo la diversificación de los tipos de cuestiones propuestas y las actividades solicitadas, involucrando diversos formatos de interacción y participación en esos espacios de aprendizaje.

Palabras-clave: Foro en línea. Educación a distancia. Colaboración. Aprendizaje colaborativa.

\section{Introdução}

As crescentes modificações ocorridas na sociedade nos últimos anos e o progresso das tecnologias informacionais abriram espaços para novas possibilidades comunicativas e educativas. Com a ampliação do uso das tecnologias - como o computador e a Internet - a comunicação humana foi potencializada. Consequentemente, novas concepções de tempo e espaço puderam ser experienciadas e a virtualidade tornou-se algo palpável. Na vertente educativa, o que se tem é um cenário em que grandes contingentes populacionais já estudam on-line (em diversos formatos de educação a distância como o e-learning e o $m$-learning ${ }^{1}$ ). A oferta de novas ferramentas comunicativas potencializou este processo, mas o que se observa atualmente é que não basta mais apenas o acesso à tecnologia para garantir o êxito pedagógico. Passada a euforia inicial que se verificou nas primeiras décadas de uso da internet para os estudos, observa-se que é preciso rever esta tecnologia de informação, expressa aqui pela internet, para mais que a mera disseminação de conteúdos. É possível encontrar diversos conteúdos online, mas isso não é sinônimo de processo educativo.

${ }^{1}$ M-learning ou mobile learning é uma forma mais avançada de e-learning e que se caracteriza, basicamente, pelo uso de dispositivos móveis como celulares e tablets para fins educativos. 
A educação, entendida aqui como algo maior que a forma escolarizada e institucionalizada, se faz no encontro com o Outro, no compartilhamento (FREIRE, 1983; LÉVINAS, 2005). Historicamente, a incorporação das tecnologias às propostas que envolvem a educação a distância (EAD) tem se dado no sentido de permitir maior aproximação entre professor e alunos, mas é preciso avançar e alcançar a formação de um espaço efetivo de colaboração que se pauta pela construção conjunta de algo maior (SÁNCHEZ ROMERO, 2015). Tendo em vista este ideal, é importante estabelecer, na educação a distância, espaços com estratégias inovadoras para o desenvolvimento de habilidades colaborativas. Nesse aspecto, os fóruns têm muito potencial para fomentar processos de comunicação assíncrona, colaborativa e potencializadora do diálogo mediado. Não se trata apenas de deixar registrada uma participação nos espaços on-line, mas sim de potencializar novos papéis colaborativos que efetivamente transformem o discente em protagonista do processo de ensino e aprendizagem.

É importante destacar que, durante muito tempo, uma visão mais tradicional da Pedagogia creditou unicamente ao professor o sucesso ou o fracasso da aprendizagem do aluno. Tal visão teve seu reflexo também na $\mathrm{EAD}$, pois o professor era frequentemente invocado como aquele que deveria ser o animador dos espaços on-line (PALLOFF; PRATT, 2002) ou ainda um "assessor pedagógico" (GUTIÉRREZ; PRIETO, 1994). O papel do aluno acabava sendo delegado a um segundo plano. Contemporaneamente, já se admite igualmente a importância dos Sujeitos envolvidos no processo de forma equânime. Além disso, pretende-se contribuir para a construção de reflexões mais amplas e sistematizar formatos de trabalho em coletividades on-line com grande número de participantes para o processo de ensino e aprendizagem (DIAS, 2013). As análises estabelecidas aqui partem do seguinte questionamento: como utilizar os elementos (ferramentas pedagógicas) da educação a distância, especificamente os fóruns on-line, como espaços estratégicos para o desenvolvimento de habilidades colaborativas para aprendizagem dos estudantes? Esse questionamento partiu de experiências e práticas atualmente em desenvolvimento 
na Universidade Aberta - UAb (Portugal) e na Universidad Nacional de Educación a Distancia - UNED (Espanha).

Adotando uma abordagem qualitativa, a investigação foi desenvolvida por meio de uma análise suportada por referenciais bibliográficos, reflexões e discussões realizadas nos espaços de reflexão do Grupo de Innovación Transdisciplinar e Internacional para el Desarrollo de Competencias Discentes y Docentes en Educación Superior da Universidad Nacional de Educación a Distancia (UNED) na Espanha.

\section{Aprendizagem colaborativa e a distância}

Assumindo que a educação a distância (EAD) pode ser caracterizada como toda e qualquer atividade de ensino e aprendizagem que ocorra com a separação física entre professor e aluno, as ferramentas comunicacionais adquirem papel crucial como possibilitadoras da mediação entre os Sujeitos. O aprendizado à distância com o uso de recursos eletrônicos é denominado e-learning (do original, electronic learning) e vem sendo bastante utilizado como forma de oferecer cursos livres, capacitação empresarial etc. Por essa razão, ainda que de maneira conceitualmente equivocada, o termo acaba sendo empregado como se fosse voltado apenas para o âmbito empresarial. Em essência, o e-learning é tão somente uma forma de EAD com o uso de recursos tecnológicos mais avançados. Tomando por base o e-learning, Connolly e Stansfield (2006) propuseram uma sexta geração de $\mathrm{EAD}$, em que esta última encontra-se fortemente marcada pela possibilidade de aprendizagem por meio de dispositivos móveis, como telefones celulares (mobile learning ou m-learning) e tablets. Os autores trabalham a ideia de aprendizagem por jogos como um traço dessa sexta geração, além da emergência das comunidades de aprendizagem que vêm formando verdadeiras redes de aprendizagem on-line. Nesse sentido, a sexta geração - respaldada no princípio das redes e em suportes cada vez menores - tem possibilitado mais vantagens para o aprendizado universitário (BARROS, 2004), como: redução de espaço e tempo, o que permite a aprendizagem centrada no aluno, redução de custos e monitoramento, 
bem como supervisão do aluno de forma mais próxima. Além disso, é preciso citar também o fato de que as competências interativas e comunicativas se desenvolveram e, por meio delas, também as práticas de empatia, confiança e colaboração (MEDINA RIVILLA; DOMÍNGUEZ GARRIDO; SÁNCHEZ ROMERO, 2013). A aprendizagem colaborativa, neste contexto, traduz-se como a essência das estratégias e do formato pedagógico dos cursos com inovação.

\section{Fóruns on-line colaborativos}

Tradicionalmente, os fóruns on-line são concebidos como espaços de diálogo assíncrono entre estudantes e professor em plataformas de educação a distância. Estes espaços são abertos e permitem que os alunos troquem experiências e compartilhem dúvidas, pontos de vista, façam debates etc. Os fóruns são, portanto, um dos principais espaços proporcionadores de comunicação horizontal nos ambientes virtuais de aprendizagem. A proposta dos fóruns, no entanto, como bem destaca Titsworth (2017) é, justamente, resgatar o aspecto interpessoal da comunicação. Mais que simplesmente rastros de passagem dos Sujeitos, é importante que estes espaços proporcionem agregação social. A pesquisa conduzida por Mohamad e Shaharuddin (2014) demonstrou que, quando efetivamente utilizados, proporcionam o engajamento e o desenvolvimento da sensação de comunidade de aprendizagem. Este engajamento tem o potencial de manter a motivação do aluno de EAD. O compartilhamento das dificuldades e também dos sucessos ajuda na visualização do Sujeito que está do outro lado do aparato tecnológico (MOKOENA, 2017), repondo a discussão feita por Linard em 1990 e resgatada em 2002: mais que aparatos tecnológicos, é preciso que exista a percepção do humano nos espaços de formação.

Freire (1983), por sua vez, partiu do princípio de que a comunicação é o que transforma essencialmente os homens em Sujeitos. Com esta base, formulou sua proposição fundamental de que a educação, como construção compartilhada de conhecimentos, constitui um processo de 
comunicação no diálogo, proporcionado por meio de relações igualitárias entre os seres humanos e o mundo.

De forma complementar, destaca-se o ponto de vista de Marcondes Filho (2010), para quem Comunicação é algo muito maior, livre de materialidade. Ela se estabelece, entre outros aspectos, na relação com o outro, no princípio da alteridade, e é por essa razão que o Outro recebe especial atenção por parte de Ciro Marcondes Filho (2010). Também Buber (2001) faz uma importante reflexão (resgatada por Marcondes Filho) a respeito do TU e do ISSO. Ao basear-se na óptica de Lévinas, Marcondes Filho defende que o Outro, no fenômeno comunicacional, é tal como é em Lévinas: impenetrável, insondável, aquele que está fora de mim. Não necessariamente se está falando de uma pessoa, mas sim daquilo que o ser não é e, exatamente por isso, rompe o ego e possibilita ver além de si mesmo. Os fóruns on-line não devem gerar, nesta perspectiva, sempre concordância. Ademais, a discordância potencializa o debate, a pesquisa, a troca enfim. O fato de serem assíncronos permite, inclusive, que o Sujeito elabore e reelabore suas visões para, então, colaborar com o debate numa perspectiva maior e autônoma. Colaborar (de raiz latina co-labor) pressupõe trabalho coletivo e o compartilhamento de responsabilidades. A concepção que reside no ato de colaborar é maior, no entanto, do que simplesmente disponibilizar um pouco (ou partes) do conhecimento próprio para auxiliar o Outro. Colaborar implica abrir-se ao Outro. Embora sejam muitas vezes utilizados como sinônimos, os termos cooperação e colaboração têm sentidos distintos. Dillembourg e Larocque (apud NITZKE; CARNEIRO; GELLER, 1999) entendem que a diferença entre a cooperação e a colaboração está na forma como a tarefa é organizada pelo grupo. Na situação de colaboração todos trabalham em conjunto rumo a um objetivo, sem definições hierárquicas. Em contrapartida, na cooperação existe a estrutura hierárquica que viabiliza a coordenação do grupo. Panitz (1996, p. 1), no entanto, sintetiza os termos ao afirmar que: "A colaboração é uma filosofia de interação e um estilo de vida pessoal, enquanto que a cooperação é uma estrutura de interação projetada para facilitar a realização de um objetivo ou produto final". Nas análises de Tractenberg 
(2011, p. 79), "cultura de colaboração" deve ser compreendida como um conjunto de conhecimentos, crenças, valores, símbolos, costumes e práticas de um grupo social que tem como base ou como finalidade a cooperação, isto é, o trabalho conjunto e interdependente.

A aprendizagem colaborativa pode ser compreendida como um conjunto de métodos e técnicas de aprendizagem desenvolvidas em grupos, que envolvem elementos sociais e pessoais (competências) em que cada pessoa é responsável por sua aprendizagem e, de certa forma, pela aprendizagem dos demais (PALLOFF; PRATT, 2002). Na aprendizagem colaborativa, a ênfase está na interação entre os participantes. Cabe aos facilitadores ou moderadores propiciarem situações de aprendizagem em que todos aprendam com todos (PALLOFF; PRATT, 2002). Dias (2012), por sua vez, menciona que na aprendizagem colaborativa os estudantes são encorajados ou solicitados para trabalharem em conjunto na construção do conhecimento.

Assim como ocorre com outras ferramentas educativas, os fóruns também exigem diferentes competências. Além da competência para a gestão do espaço, é preciso que o educador (professor) também desenvolva diferentes competências. Tais competências pressupõem abertura para o diálogo e presença virtual. Diferentemente do que ocorre em situações de educação face a face, nos espaços virtuais os alunos percebem a presença do professor por meio de seus registros nos fóruns e demais ferramentas. O fórum é o espaço para a fala não institucionalizada e, portanto, mais pessoal e que pode estabelecer um maior vínculo por meio da aproximação. É importante que os professores destinem atividades (respostas) específicas para os estudantes, de forma a incentivar a colaboração e a partilha de responsabilidade. Aos educadores cabe a tarefa de realizar a gestão do espaço virtual e, para tanto, é preciso que os próprios professores estejam cientes da importância que desempenham na condução deste tipo de estratégia pedagógica (CORICH, HUNT; 2006). 


\section{Procedimentos metodológicos}

As opções metodológicas deste estudo de caso basearam-se em uma diversidade de estratégias de coleta de dados, privilegiando aspectos quali-quanti, tendo em vista a complexidade do objeto do estudo (YIN, 2010; MERRIAM, 2009).

Tendo em vista o objetivo geral do estudo, os contextos estudados estão relacionados à potencialização do uso pedagógico dos fóruns on-line em EAD. Para tal, dois grupos foram selecionados para observação e intervenção, sendo eles: grupo 1 - alunos de pós-graduação de uma disciplina da área de Educação da Universidade Aberta (UAb) de Portugal e grupo 2 - alunos de graduação de uma disciplina igualmente da área de Educação da Universidad Nacional de Educación a Distancia (UNED) de Espanha.

A seleção desses grupos se deu em função de dois aspectos. O primeiro deles diz respeito à necessidade de rigor metodológico para análise de estudos de casos e, mais especificamente, análises de casos múltiplos e o segundo ponto refere-se ao histórico das instituições no tocante à EAD. Com relação ao primeiro aspecto, Yin (2010, p. 69) estabelece que, em estudos de casos múltiplos, cada caso deve ser selecionado de forma a “a) prever resultados semelhantes (uma replicação literal); ou b) produzir resultados contrastantes apenas por razões previsíveis (uma replicação teórica)". Não há, portanto, a necessidade de uma amostragem em termos probabilísticos. Ao contrário disso, a seleção dos casos deve levar em consideração a relevância deles para o que o estudo pretende desvelar. A segurança metodológica em casos múltiplos está na lógica da replicação, segundo a qual os resultados devem permitir certa replicação em contextos distintos. Isto posto, a seleção aqui realizada contempla as especificidades destacadas pelo aparato metodológico selecionado: por um lado, trata-se de alunos oriundos da EAD (portanto, este fato permite replicação literal), mas, por outro lado, estes mesmos alunos são oriundos de instituições diferentes e estão em níveis distintos da carreira acadêmica 
— graduação e pós-graduação — (este fato permite, por sua vez, replicação teórica).

No que se refere às instituições selecionadas, portanto, segundo aspecto aqui colocado, destaca-se que a Universidade Aberta de Lisboa é uma instituição de pequeno porte, mas que tem um modelo pedagógico premiado por ser o primeiro modelo de e-learning em língua portuguesa. A plataforma utilizada é o Moodle 3.0 customizada para o modelo pedagógico da Universidade, cujos 150 professores atendem cerca de dez mil alunos em todos os países de língua portuguesa ${ }^{2}$. Para fins deste estudo, a coleta de dados incluiu os registros de interação do fórum de uma disciplina do curso de pós-graduação em Educação Social. Quanto ao perfil destes alunos, pode-se afirmar que a maior parte tem mais de 30 anos, trabalha e tem filhos. A relação que estabelecem com a educação é muito clara: os alunos buscam crescer na carreira profissional ou conseguir um outro emprego na área específica da pós-graduação.

Diferentemente da Universidade Aberta, a Universidad Nacional de Educación a Distancia se caracteriza por ser de grande porte. $\mathrm{Na}$ Universidad Nacional de Educación a Distancia (UNED) na Espanha, o fórum é uma ferramenta na plataforma aLF — ambiente virtual de aprendizagem criado pela própria instituição. A UNED atualmente opera em vários países de língua espanhola para auxiliar seus mais de $250 \mathrm{mil}$ alunos e professores ${ }^{3}$. Para fins de pesquisa, a coleta de dados incluiu os registros de interação do fórum de uma disciplina do curso de graduação em Educação Social. A pesquisa prévia realizada por Santos (2013) revelou o perfil dos alunos deste curso: a maioria tem mais de 25 anos, trabalha e tem filhos. Tal como ocorre na UAb, a relação que os estudantes da UNED estabelecem com a educação objetiva o progresso na carreira e consequente melhora salarial.

2 Informações disponíveis no site oficial da Universidade, disponível em: <http://portal.uab.pt/>. Acesso em: 31 jul. 2018.

${ }^{3}$ Informações disponíveis no site oficial da Universidade, disponível em: <http://portal.uned.es/ portal/page?_pageid=93,1\&_dad=portal\&_schema=PORTAL>. Acesso em: 31 jul. 2018. 


\section{Estruturação dos fóruns e coleta de dados}

As observações nas duas disciplinas aqui mencionadas ocorreram no segundo semestre de 2016. No total, foram cerca de quinze semanas de aula. Essas observações foram semanais e os registros priorizaram a quantidade de participações e intervenções dos estudantes nos diversos tipos de posts disponibilizados nos fóruns, de acordo com a sua organização. Os fóruns foram organizados a partir de estratégias pedagógicas diferenciadas, segundo os diferentes estilos de uso do espaço virtual. Sobre este aspecto, é salutar destacar que Barros (2004; 2009; 2013) caracteriza os estilos de uso do espaço virtual a partir dos estilos de aprendizagem (ALONSO; GALLEGO; HONEY, 2012), considerando o paradigma e as características dos processos de aprendizagem no ambiente virtual.

\section{Resultados}

As tabelas que seguem apresentam os elementos de observação dos fóruns e as particularidades no uso de cada fórum em relação ao tipo de interação dos estudantes e às habilidades colaborativas de aprendizagem. Partindo da assunção de que, de acordo com Yin (2010, p. 75): “[...] cada estudo de caso pode incluir, na verdade, a coleta e a análise de dados altamente quantitativos, incluindo a utilização de levantamentos em cada caso", as Tabelas 1 e 2 referem-se, respectivamente, às dinâmicas realizadas na UAb (Portugal) e na UNED (Espanha). Além das dinâmicas, as tabelas apresentam também dados quantitativos percentuais. 
Tabela 1 - Uso dos Fóruns - Universidade Aberta (Portugal) (continua) Disciplina Disciplina (em anonimato) no curso em Educação Social (disciplina de pós-graduação)

Número de 15 estudantes realizaram o primeiro ano do curso de pós-graduação. Ressalte-se que alunos estes estudantes já haviam sido estudantes da Universidade em anos anteriores e já estavam familiarizados com o modelo pedagógico e o trabalho on-line. Para além disso, já possuíam as habilidades para desenvolverem atividades a distância.

Temas $\quad$ 1. Como identificar a necessidade de um projeto social;

desenvolvidos 2. Quais os itens de um projeto social;

/período 3. Como estruturar um projeto social;

4. Desenvolvimento de um projeto social.

Estratégia No total, 3 fóruns foram desenvolvidos durante a disciplina. Aqui consideramos didática somente os fóruns de conteúdo dos temas. Cada fórum teve um tema específico, com duração de duas semanas. A participação nos fóruns foi sempre considerada como quesito obrigatório no somatório da avaliação final.

- O primeiro fórum teve como objetivo identificar os novos paradigmas dos projetos sociais, suas necessidades, tendências e perspectivas.

Para este fórum, os estudantes deveriam estudar o material de leitura de um texto sobre o paradigma de projetos. Em seguida, de acordo com as perguntas colocadas em posts diversificados, os discentes deveriam responder e dialogar com o colega. Essas perguntas estavam caracterizadas como afirmações, questionamentos e atividades gerais, como elaboração de um breve mapa sobre o tema estudado ou a indicação de sites com uma breve síntese de conteúdos relacionados. Essas perguntas e atividades estavam elaboradas de acordo com os estilos de aprendizagem, organizadas em formatos que contemplavam os diversos estilos de aprender. Os estudantes deveriam ter no mínimo 3 participações no fórum, independentemente da atividade que realizassem. Dentre essas atividades, uma delas foi proposta para trabalhar em grupo.

- No segundo fórum, o tema desenvolvido versou sobre a importância de um projeto de intervenção social e seu significado. Para este fórum, para além da leitura de dois capítulos do livro da disciplina, os alunos tiveram que encontrar e partilhar projetos através de uma pesquisa on-line sobre a intervenção social. Após esta busca, fizeram um resumo breve do projeto e disponibilizaram o link. Além dessa atividade de estudo, os discentes deveriam participar nos fóruns com os posts diversificados de acordo com os estilos de aprendizagem. Neste caso, havia perguntas de análise crítica, solicitação de breves sínteses sobre o que se aprendeu e a partilha de vídeos sobre experiências e projetos já desenvolvidos. Dentre essas atividades, uma delas foi proposta com dinâmica de trabalho em grupo.

- O terceiro fórum focou a construção de um mapa conceitual com um aplicativo específico que privilegiou diretamente a colaboração e a coaprendizagem (LITEMAP4). Este aplicativo é estruturado para elaboração de mapas conceituais em colaboração, utilizando e reutilizando conteúdos e aplicativos da web. Além disso, o LITEMAP apresenta uma interface amigável e muito colaborativa, permite interação, sugestão e opinião sobre os mapas realizados. $\mathrm{O}$ trabalho realizado pelos estudantes versou sobre a estrutura de um projeto social (elementos que deveriam constar), com posterior partilha entre os colegas que deveriam dar sugestões e opiniões.

${ }^{4}$ Disponível em: <https://litemap.net>. Acesso em: 25 mar. 2018. 
Critérios de avaliação

Interação

Habilidades Colaborativas identificadas Observações
gerais
- Deveriam ter, no mínimo, 3 participações;

(conclusão)

- Seguir uma Net-etiqueta, ou seja, escrever as mensagens cumprimentando os colegas, desenvolvendo o assunto e finalizando com uma saudação;

- Os conteúdos e as análises críticas solicitadas deveriam ter por base os materiais e textos indicados na disciplina e deveriam ser citados nas argumentações realizadas;

- As atividades solicitadas deveriam ser desenvolvidas plenamente de acordo com a escolha feita.

Fóruns abertos e com orientações para a interação em todos os momentos, de forma assíncrona e espontânea, de acordo com as exigências para cada fórum.

Interação entre aluno e docente correu de forma normal, com as intervenções e o estímulo motivacional do docente para que as atividades, participações e exercícios fossem realizados.

Interação entre aluno e aluno ocorreu de forma mais intensiva nos posts e atividades propostas.

Considerando cada item (atividade ou exercício) do fórum, as porcentagens a seguir foram calculadas a partir da observação das participações dos estudantes:

Os estudantes passaram a colaborar entre si na realização das atividades solicitadas de acordo com as preferências. Cerca de $30 \%$ nas participações.

Pequenos grupos surgiram na realização das atividades, mesmo sem serem solicitados. Cerca de $10 \%$ nas participações.

Nas propostas para o trabalho em grupo a organização entre os estudantes surgiu espontaneamente e livre. Cerca de $50 \%$ dos estudantes fizeram essa auto-organização.

Os mesmos grupos se repetiram por afinidade. Os estudantes não foram obrigados a trabalhar em grupos formados pelos docentes, mas sim por eles próprios.

Participações de acordo com as atividades solicitadas (100\%).

Também se observou o feedback individual entre os estudantes sobre o que os colegas estavam a realizar. Surgiu uma avaliação entre pares com sugestões e concordância sobre o trabalho do outro (80\%).

Todos os fóruns proporcionados tiveram participações. A grande maioria dos alunos realizava vários dos posts solicitados nos fóruns e alguns preferiram somente um tipo de fórum. A interação ocorreu na medida em que iam visualizando aquilo que os colegas realizavam, então os alunos opinavam e tentavam fazer igual ou melhor. A atividade proposta para realização em grupo teve adesão, mas não tanto quanto se esperava. O mais interessante é que os estudantes se envolveram na dinâmica das possibilidades, sentindo-se livres para fazerem escolhas de acordo com suas preferências. Isso, de certa forma, motivou e facilitou o desenvolvimento deles na disciplina.

Fonte: Desenvolvido pelas autoras (2018).

No caso da UNED (Tabela 2), os resultados demonstram a dinâmica ensejada para o uso de fóruns na graduação. Importante destacar que, neste caso, o número de alunos era muito maior (120 alunos). Tal característica fez com que a estratégia precisasse ser repensada para este contexto mais amplo: ao invés de destacar as características de uso do 
espaço on-line de forma mais direta (tal como ocorreu na UAb), a UNED privilegiou tais pontos de forma indireta e, em grande medida, pensando no fomento ao debate entre os próprios alunos.

Tabela 2 - Uso dos Fóruns - UNED (Espanha) (continua)

$\begin{array}{ll}\text { Disciplina } & \text { Disciplina (em anonimato) no curso em Educação Social (disciplina de } \\ \text { graduação) }\end{array}$

\section{Quantidade de alunos matriculados/ participantes}

Temas desenvolvidos

\section{Estratégia didática}

Interação

\author{
120 estudantes
}

O trabalho foi realizado sobre a intervenção socioeducativa em diferentes contextos vulneráveis, desde a conceitualização das estratégias didáticas até os fatores de risco. Para a análise, solicitou-se que os discentes considerassem:

- Dificuldades na Infância (enfermidade, exclusão, integração)

- Dificuldades na Juventude (problemas com o consumo de drogas)

- Dificuldades em outros coletivos (mulheres maltratadas e pessoas privadas de liberdade).

Debate Dirigido nos Fóruns. Esse debate desenvolveu-se dentro de cada fórum, com os seguintes tipos de perguntas realizadas: mais reflexivas, mais críticas, mais informativas ou mais de conteúdo somente. Cada um dos três fóruns de conteúdos disponibilizados durante o semestre abordou o tema em destaque. Para cada tema, cerca de quatro posts para que os estudantes pudessem dialogar nas perguntas realizadas. Os tipos de perguntas realizadas foram abertos: não estruturadas, abertas para reflexão crítica, para argumentação e informativas em relação ao conteúdo. Os tipos de perguntas estavam relacionados também com os estilos de aprender individuais.

- O primeiro fórum teve como objetivo identificar os novos paradigmas dos projetos sociais, suas necessidades, tendências e perspectivas.

- No segundo fórum o tema em desenvolvimento era as dificuldades na juventude.

- O terceiro fórum focou o debate nas dificuldades em outros grupos sociais vulneráveis.

Fóruns abertos e com orientações para a interação em todos os momentos de forma assíncrona e espontânea.

Interação entre aluno e docente foi pautada pelo estímulo motivacional do docente para que as atividades, participações e exercícios fossem realizados.

Interação entre aluno e aluno ocorreu de forma mais intensiva nos posts dos diversos fóruns. 
Habilidades

Colaborativas identificadas

Observações gerais
Considerando cada item (tipo de pergunta) do fórum, as

(conclusão) porcentagens a seguir foram calculadas a partir da observação das participações dos estudantes:

Os estudantes passaram a colaborar entre si na realização das atividades solicitadas de acordo com as preferências (cerca de $40 \%$ nas participações).

Nas propostas para o trabalho em grupo, a organização entre os estudantes surgiu espontaneamente (cerca de $80 \%$ dos alunos fizeram essa auto-organização).

Os mesmos grupos se repetiram por afinidade. Os estudantes não foram obrigados a trabalhar em grupos formados pelos docentes, mas sim por eles próprios.

Participações de acordo com as atividades solicitadas (90\%).

Também se observou o feedback individual entre os estudantes sobre o que os colegas estavam realizando (cerca de $60 \%$ ).

Todos os fóruns proporcionados tiveram participações. A grande maioria dos alunos realizava vários dos posts solicitados nos fóruns. A interação ocorreu na medida em que iam visualizando o que os colegas realizavam, opinavam e tentavam fazer igual ou melhor. $O$ mais interessante é que os estudantes se envolveram na dinâmica das possibilidades, sentindo-se livres para fazerem escolhas de acordo com suas preferências.

Fonte: Desenvolvido pelas autoras (2018).

Para além das observaç̃oes expostas nas Tabelas 1 e 2, ao final nas duas disciplinas foi enviada uma pergunta única aos estudantes com o objetivo de saber como os alunos avaliavam a experiência nos fóruns. A síntese das respostas dos dois grupos pode ser visualizada na Tabela $3^{5}$.

${ }^{5}$ Optamos aqui por não desenvolver um quadro de estatística descritiva em função da quantidade irregular de respostas em um número representativo. Apresenta-se, portanto, somente a expressão da participação (tal como redigida pelos próprios discentes) nos fóruns das disciplinas. 
Tabela 3 - Compilação da participação nos fóruns

\begin{tabular}{ll}
\hline \hline Pergunta: & Síntese de respostas \\
\hline \hline Como foi sua & - Para tirar dúvidas sobre o tema da disciplina. \\
participaço nos fóruns & - Para contatar diretamente os docentes e os demais. \\
& - Poderia dizer que é um recurso educativo, didático e formativo de \\
& muita utilidade. \\
& Incluir documentos interessantes da disciplina ou outro material \\
& - Recompilar a informação dos docentes e colegas. \\
& - Seguir diariamente as mensagens. \\
& - Leitura de todas as mensagens \\
& - Participei de diversas formas no fórum. \\
& - Fiquei motivada com a participação. \\
& - Algumas mensagens repetidas. \\
& - Para recolher algum documento interessante disponibilizado. \\
& - Gostei da troca em grupo. \\
& - Comunicar com o professor e sentir que os demais colegas me \\
& acompanhavam e estavam presentes. \\
& - Participei em um tipo de fórum somente. \\
& - Fiz várias atividades. \\
& - Respondi todas as perguntas. \\
\hline \hline
\end{tabular}

Fonte: Desenvolvido pelas autoras (2018).

A apresentação dos dados somada à observação experiente das docentes das disciplinas e, sobretudo, tendo em vista o aparato teórico-metodológico proporcionaram que o presente estudo apresente uma revisita no que se refere ao uso de fóruns on-line na educação a distância. As reflexões são apresentadas no item que segue.

\section{Estratégias para o desenvolvimento de habilidades colaborativas}

O trabalho com os fóruns possibilitou desenvolvimento didático e pedagógico mais ativo durante as disciplinas. O direcionamento das discussões e o desenvolvimento das estratégias e fases de trabalho em cada fórum proporcionaram a construção de um espaço de exercícios e atividades de interação entre docentes e entre estudantes. Os estudantes tiveram dificuldade de participar no início e de se integrarem à dinâmica orientada, mas aos poucos foram se motivando e realizando as atividades de forma cada vez mais colaborativa. 
As diferenças entre os fóruns das disciplinas foram exatamente o uso dos aplicativos e interfaces on-line na solicitação de atividades, bem como o uso das estratégias didáticas e pedagógicas a partir da teoria dos estilos de aprendizagem no grupo. Além disso, deve-se dar relevo também à versão do fórum para um grupo de estudantes mais restrito que foi ampliada com atividades e estratégias diversificadas. No caso do fórum com maior número de estudantes, optou-se por diversificar e ampliar os tipos de perguntas. Essas diferenças entre os fóruns ocorreram considerando duas variáveis específicas: a quantidade de estudantes (15 e 120) e o nível de formação (graduação e pós-graduação).

Foi possível perceber, durante o processo de observação, que os estudantes do fórum da Tabela 1 estiveram mais envolvidos e direcionados para as atividades pretendidas. Isso possibilitou pensar que a inserção de ferramentas e interfaces juntamente com estratégias amplas a partir de diferentes formatos e dinâmicas proporcionadas construíram um ambiente flexível e facilitador para o trabalho colaborativo. Esse grupo é constituído por alunos de pós-graduação com maior nível de autonomia e comprometimento. Para além disso, como já mencionado, são estudantes com fluência em um modelo de ensino e aprendizagem on-line. Essas características contribuem para uma ação, participação e interação diferenciadas nos fóruns. Mesmo com mais habilidades em relação ao outro grupo, este conjunto ainda teve dificuldades no trabalho com as habilidades colaborativas, objeto aqui do estudo realizado.

As habilidades de colaboração pressupõem muito além das estratégias de orientação das atividades, a ambiência de uso do espaço, um nível de confiança no grupo e uma motivação inerentes ao processo. Foi possível perceber que metade da turma interagiu de forma colaborativa a partir dos tipos de fóruns propostos. Isso é um indicador muito importante para as habilidades de trabalho colaborativo. Esses elementos passam pelo que Dias (2012; 2013) menciona como sendo a construção de uma cultura de rede dentro dos próprios espaços de aprendizagem.

A Tabela 2, por sua vez, demonstra que somente a interação no fórum com perguntas e comunicação linear não foi tão motivadora para 
que os estudantes interagissem e agissem de forma mais colaborativa. A participação e interação sobre as postagens dos colegas foi o momento de interação mais motivador das habilidades colaborativas. A colaboração mais competitiva esteve presente nas argumentações no sentido de postar mais que o outro, ou aprofundar o que o outro mencionou. Verificou-se também que a diversificação dos tipos de perguntas nos fóruns é um fator diferenciador e que pode motivar um processo maior de interação e desenvolvimento das habilidades colaborativas.

Pode-se analisar que em geral foram destacadas situações mais individuais de proveito próprio, mas também outras situações de partilha e colaboração com o grupo. Uma série de indicadores iniciais foram levantados no que se refere às habilidades de colaboração que podem ser desenvolvidas com os dispositivos pedagógicos dos fóruns como espaço de comunicação mais ativa e direcionada. As estratégias proporcionadas motivaram e instigaram reações diferenciadas que chegaram de certa forma ao trabalho colaborativo. São indicadores que demonstram que os estudantes podem ser motivados e estimulados para a colaboração através dos dispositivos pedagógicos de incentivo das docentes (a interatividade pedagógica). Nesse sentido, é necessário ressaltar que o desenvolvimento desta interatividade só se faz mediante domínio das competências voltadas para o uso das TIC, tais como: busca de informação qualificada em espaços virtuais, problematização dos conteúdos acessados e produção efetiva de conteúdo para ambientes virtuais (isso quer dizer: mais que apenas acessar, é importante que o Sujeito produza algo para a rede e contribua para com o novo ambiente).

Mas, não são apenas estas competências que contam. Há que se levar em consideração a distinção entre acessar e participar. Ficou claro que os alunos só conseguem desenvolver suas habilidades colaborativas à medida que conseguem participar do que se propõe. A competência colaborativa é mais que apenas compartilhar conteúdos. Ela pressupõe o trabalho coletivo e a partilha de responsabilidades. $\mathrm{O}$ aluno deixa de ser aluno para se tornar co-partícipe de seu desenvolvimento (ROTHWELL, 2013). 
Esse sentimento, conforme verificado por Mazzolini e Maddison (2007), nada tem a ver com o número de postagens realizadas.

Ademais, esta pesquisa encontrou resultados muito semelhantes aos de Gritsenko (2016) nos Estados Unidos: "online fórums introduce limitations to interactions, discussion threads can indeed be viewed as group communication" ${ }^{6}$. De fato, esta pesquisa mostrou que o sentimento de grupo nasce justamente com o pertencimento, estabelecimento de vínculo. Isso fica claro quando levamos em consideração a fala dos discentes, expressa pelas respostas abertas. Quando o fórum deixa de ser apenas ferramenta, ele se torna um espaço de encontro que proporciona aos alunos a sensação de estarem acompanhados (CABERO, 2006). Podemos então sintetizar na Tabela 4 , a partir da proposta realizada nas duas disciplinas, a seguinte sequência de estratégias a serem aplicadas nos fóruns on-line com o intuito de estimular o desenvolvimento de habilidades colaborativas. Nesse sentido, a inovação desta proposta está em potencializar o uso do fórum para além de um espaço de comunicação, mas sim de participação e desenvolvimento de habilidades de colaboração para a aprendizagem.

6 "Os fóruns online apresentam limitações às interações, os tópicos de discussão podem, de fato, serem vistos como comunicação grupal” (tradução livre). 
Tabela 4 -Estratégias didáticas e pedagógicas.

\begin{tabular}{|c|c|}
\hline Estratégias & Descrição \\
\hline $\begin{array}{l}\text { Baseada no } \\
\text { atendimento } \\
\text { pedagógico mais } \\
\text { individualizado dos } \\
\text { estudantes }\end{array}$ & $\begin{array}{l}\text { Estratégias que passam pela elaboração de atividades diferenciadas } \\
\text { individuais e colaborativas, dentro dos fóruns assíncronos. É } \\
\text { importante que as atividades propostas permitam a postagem } \\
\text { individual e o comentário colaborativo. Ou, outra opção: a postagem } \\
\text { em grupo e o comentário colaborativo. Como proposta, sugere-se: } \\
\text { - elaboração de um breve mapa conceitual sobre o tema estudado; } \\
\text { - indicação de sites com uma breve síntese de conteúdos } \\
\text { relacionados; } \\
\text { - encontrar e partilhar projetos relacionados ao tema em estudo } \\
\text { - através de uma pesquisa on-line; } \\
\text { - fazer um resumo breve do link encontrado e disponibilizar no } \\
\text { - breve síntese sobre o que se aprendeu dando sua opinião; } \\
\text { - partilha de vídeos sobre experiências já desenvolvidas; } \\
\text { - elaboração de um quadro/ tabela pessoal sobre o que sabia sobre } \\
\text { o conteúdo e o que aprendeu; } \\
\text { - disponibilizção de uma imagem representativa sobre o tema. }\end{array}$ \\
\hline $\begin{array}{l}\text { Baseadas na tipologia } \\
\text { de perguntas nos fóruns }\end{array}$ & $\begin{array}{l}\text { Estratégias que passam pela elaboração de diferentes tipos de } \\
\text { perguntas para argumentação e interação nos fóruns. } \\
\text { - perguntas não estruturadas, abertas para reflexão crítica; } \\
\text { - perguntas para argumentação; } \\
\text { - perguntas informativas em relação ao conteúdo; } \\
\text { - perguntas de contradição para que analisem os diversos caminhos } \\
\text { sobre o tema; } \\
\text { - perguntas sobre exemplos práticos que envolvem o conteúdo; } \\
\text { - perguntas conceituais ou históricas sobre o tema; } \\
\text { - perguntas para caracterizar os elementos do tema. }\end{array}$ \\
\hline $\begin{array}{l}\text { Interfaces potenciais } \\
\text { para o processo } \\
\text { de comunicação e } \\
\text { desenvolvimento } \\
\text { de habilidades } \\
\text { colaborativas para além } \\
\text { dos fóruns on-line }\end{array}$ & $\begin{array}{l}\text { Estratégias utilizando interfaces on-line (assíncronas) para } \\
\text { dinamizar o uso das tecnologias como potencializadoras do trabalho } \\
\text { colaborativo. É importante que a proposta de elaboração de debates } \\
\text { e argumentações sobre determinados tópicos do conteúdo utilize: } \\
\text { - Wikis; } \\
\text { - Blogs; } \\
\text { - Google docs; } \\
\text { - Whatsapp; } \\
\text { - Facebook; } \\
\text { - Aplicativos de mapa conceitual interativo como o LITEMAP; } \\
\text { Todas essas interfaces podem ser utilizadas com uma orientação } \\
\text { bem definida com: objetivos, período de realização, grupo, } \\
\text { atividades, formas de participação, quantidade de participação, } \\
\text { exigências mínimas e critérios de avaliação. } \\
\text { É importante que a proposta contemple as orientações para o } \\
\text { uso de aplicativo e a atividade a ser realizada, de comunicação } \\
\text { assíncrona e colaborativa. }\end{array}$ \\
\hline
\end{tabular}

Fonte: Desenvolvido pelas autoras (2018). 
Esta proposta se aplica a todo modelo pedagógico de educação a distância, e-learning ou m-learning, para além dos espaços formais de aprendizagem. É uma proposta flexível, baseada nos princípios da aprendizagem on-line e dos paradigmas do virtual e da cibercultura. Além disso, tem por elementos caracterizadores os processos de comunicação, interação, participação, construção e presença colaborativa no trabalho em comunidade. Um dos aspectos salutares está no fato de que esta proposta aborda todos os eixos para o desenvolvimento das habilidades de colaboração voltados para os processos de ensino e aprendizagem. Aprender a respeitar a opinião do Outro, ouvi-lo, argumentar a partir de seu olhar são características que mobilizam a colaboração. Trata-se, portanto, de algo que pode ser construído ou desenvolvido e, por isso, é importante fomentar estratégias didáticas que contemplam o indivíduo, mas, ao mesmo tempo, que pressuponham a abertura dele para com os demais.

\section{Considerações finais}

Este estudo permite que se visualize a potencialidade dos fóruns nos ambientes virtuais de aprendizagem, bem como sua importância. Como qualquer outra ferramenta educativa, os fóruns pressupõem o uso de uma metodologia específica para que se alcance o envolvimento dos Sujeitos envolvidos no processo. Aluno e professor precisam se sentir juntos, ainda que virtualmente. Além disso, os professores também têm que planejar suas estratégias didáticas para os fóruns, pensando sempre no tipo de retorno que será oferecido ao aluno. Uma verdadeira aprendizagem on-line precisa prever a participação. Por fim, esta pesquisa mostrou que estar em um fórum de forma completa pressupõe um aprendizado experiencial que se inicia em um nível cognitivo, ou seja, o próprio aluno deve estar aberto para isso, passar pela fase de desenvolvimento de competências em TIC, atravessar o mero acesso para alcançar a participação e, por fim, chegar ao compartilhamento de informações. Ao professor cabe o desenvolvimento de estratégias que desafiem seus alunos sem, contudo, deixá-los sem amparo. É preciso "habitar" o virtual, deixar 
rastros, marcas, pegadas que possam ser visualizadas pelo aluno, e sempre abrir-se para o diálogo.

\section{Limitações do estudo}

Todo estudo apresenta limitações. O estudo aqui apresentado tem potencial para ser realizado em outros contextos e não somente no ensino superior, mas também em outros níveis de ensino e situações voltadas para a formação on-line. Isso seria enriquecedor e nos proporcionaria mais elementos para sugerir e ampliar as estratégias aqui mencionadas. Não pretendendo esgotar as sugestões e as possibilidades nessa dimensão dos fóruns on-line e sabendo das limitações, temos este estudo dentro de um projeto maior de trabalho e que continuaremos a explorar e a analisar de forma mais ampla para aperfeiçoar os resultados aqui encontrados.

\section{Referências}

ALONSO, C. M.; GALLEGO, D. J.; HONEY, P. Los estilos de aprendizaje: procedimientos de diagnóstico y mejora. 8. ed. Madrid: Mensajero, 2012.

BARROS, S. (Org.). Las TIC en el sistema universitario español. Madrid: CRUE, 2004. BARROS, D. M. V. Estilos de uso do espaço virtual: como se aprende e se ensina no virtual? Revista Inter Ação, v. 34, n. 1, p. 51-74, 2009.

BARROS, D. M. V. Estilos de Aprendizagem e o uso das tecnologias. Santo Tirso: deFacto, 2013.

BUBER, M. Eu e tu. 8. ed. São Paulo: Centauro, 2001.

CABERO, J. Bases pedagógicas del e-learning. Revista de Universidad y Sociedad del Conocimiento (RUSC), v. 3, n. 1, 2006. Disponível em: <http://www.uoc.edu/ rusc/3/1/dt/esp/cabero.pdf $>$. Acesso em: 20 mar. 2018. 
CONNOLLY, T.; STANSFIELD, M. Developing Constructivist Learning Environments to Enhance e-Learning. In: BUZZETTO-MORE, N. A. Principles of Effective Online Teaching. Santa Rosa: Informing Science Institute, 2007.

CORICH, S. P.; HUNT, L. M. Measuring critical thinking within discussion forums using a computerised content analysis tool. In: BANKS, S. et al. (Eds.). Proceedings of the Fifth International Conference on Networked Learning. Lancaster: Lancaster University, 2006.

DIAS, P. Comunidades de educação e inovação na sociedade digital. Educação, Formação \& Tecnologias, v. 5, n. 2, p. 4-10, 2013. Disponível em: <http://eft. educom.pt>. Acesso em: 07 out. 2017.

DIAS, P. Inovação pedagógica para a sustentabilidade da educação aberta e em rede. Educação, Formação \& Tecnologias, v. 6, n. 2, p. 4-14, 2013. Disponível em: <http://eft.educom.pt>. Acesso em: 07 out. 2017.

FREIRE, P. Extensão ou comunicação? Prefácio de Jacques Chonchol. 7. ed. Rio de Janeiro: Paz e Terra, 1983.

GRITSENKO, V. Interaction on Online Forums and Group Communication: A Case Study of an IT Support Community. Procedia - Social and Behavioral Sciences, v. 236, n. 14, p. 14-24, 2016.

GUTIÉRREZ, F.; PRIETO, D. A mediação Pedagógica: educação a distância alternativa. Campinas: Papirus, 1994.

LÉVINAS, E. Entre Nós: Ensaio sobre Alteridade. 2. ed. Trad. Pergentino Stefano Pivatto. Petrópolis: Vozes, 2005.

LINARD, M. Des machines et des hommes. Paris: Éditions universitaires, 1990.

LINARD, M. Conception de dispositifs et changement de paradigme en formation. Éducation permanente, Paris, p. 143-155, 2002.

MARCONDES FILHO, C. Princípio da razão durante. São Paulo: Paulus, 2010. v.III, tomo 5: "O conceito de comunicação e a epistemologia metapórica". 
MAZZOLINI, M.; MADDISON, S. When to Jump in: the Role of the Instructor in Online Discussion Forums. Computers \& Education, v. 49, n. 2, p. 193-213, 2007. MEDINA RIVILLA, A.; DOMÍNGUEZ GARRIDO, M. C.; SÁNCHEZ ROMERO, C. Evaluación de las competencias de los estudiantes: modelos y técnicas para la valoración. Revista de Investigación Educativa, v. 31, n. 1, p. 239-255, 2013.

MERRIAM, S. B. Qualitative research: a guide to design and implementation. San Francisco: Jossey-Bass, 2009.

MOHAMAD, M.; SHAHARUDDIN, S. Online Forum Discussion to Promote Sense of Learning Community among the Group Members. International Education Studies, v. 7, n. 13, 2014.

MOKOENA, S. Student teachers' experiences of teaching practice at open and distance learning institution in South Africa. Turkish Online Journal of Distance Education-TOJDE, v. 18, n. 2, apr. 2017.

NITZKE, J. A. et al. Criação de ambientes de aprendizagem colaborativa. Simpósio Brasileiro de Informática na Educação, v. 10, 1999.

PALLOFF, R.; PRATT, K. Construindo Comunidades de Aprendizagem no Ciberespaço. Porto Alegre: Artmed, 2002.

PANITZ, T. A definition of collaborative vs cooperative learning. Deliberations, 1996. Disponível em: <http://colccti.colfinder.org/sites/default/files/a_definition_ of_collaborative_vs_cooperative_learning.pdf $\rangle$. Acesso em: 14 mar. 2017. ROTHWELL, J. D. In mixed company: communicating in small groups and teams. Boston: Waldsworth, 2013.

SÁNCHEZ ROMERO, C. Competencias TIC en Educación para la Intervención Socieducativa en contextos diversos y vulnerables. In: CACHEIRO, M. L.; SÁNCHEZ, C.; GONZÁLEZ, J. M. Recursos Tecnológicos en contextos educativos. Madrid: UNED, 2015. 
SANTOS, V. M. dos. Materiais audiovisuais para a educação a distância: a contribuição dos estilos de aprendizagem. Tese. (Doutorado em Educação Escolar) — Universidade Estadual Paulista “Júlio de Mesquita Filho”, Araraquara, 2013.

TITSWORTH, S. Forum: Interpersonal Communication in Instructional Settings - Improving Situational Awareness for Instructional Communication Research: A Forum Response. Communication Education, v. 66, n. 1, p. 122-125, 2017.

TRACTEMBERG, L. Colaboração Docente e Ensino Colaborativo na Educação Superior em Ciências, Matemática e Saúde: Contexto, Fundamentos e Revisão Sistemática. Tese (Doutoramento em Educação) — Universidade Federal do Rio de Janeiro, Rio de Janeiro, 2011.

YIN, R. K. Estudo de caso: planejamento e métodos. Trad. Ana Thorell; Rev. Téc. Cláudio Damacena. 4. ed. Porto Alegre: Bookman, 2010.

Recebido: 31/07/2018

Received: 07/31/2018

Recibido: 31/07/2018

Aprovado: 08/02/2019 Approved: 02/08/2019 Aprobado: 08/02/2019 